\title{
Aspectos sazonais sobre a fisiologia reprodutiva em lobos-guarás (Chrysocyon brachyurus, Illiger 1811) em cativeiro: revisão de literatura
}

\author{
Augusto Ryonosuke Taira, ${ }^{1}$ Karla Renata Kaminsk Andreoli ${ }^{1}$ Katherinne Maria Spercoski ${ }^{1}$ \\ ${ }^{1}$ Universidade Estadual do Centro Oeste, Campus CEDETEG, Departamento de Medicina Veterinária
}

ISSUE DOI: $10.3738 / 1982.2278 .1115$

O lobo-guará (Chrysocyon brachyurus, Illiger 1811), é um exemplar da família Canidae, pertencente ao gênero Chrysocyon, sendo o maior canídeo habitante da América do Sul. Atualmente, é considerada uma espécie quase ameaçada de extinção, principalmente pela fragmentação do seu habitat natural, o bioma do cerrado. Sendo a reprodução em cativeiro um grande desafio para a conservação da espécie, o conhecimento das características biológicas e fisiológicas da reprodução desses animais é de suma importância para adoção de práticas de manejo que melhorem seus índices reprodutivos. Em relação ao macho, estudos sugerem fortemente que o mesmo apresenta uma intensa sazonalidade no que diz respeito à qualidade espermática. De forma resumida, observam-se diferenças nas variáveis concentração espermática, volume, motilidade e vigor entre as estações reprodutiva (ER) e não reprodutiva (ENR) da espécie, indicando que os machos avaliados apresentaram ejaculados de melhor qualidade na ER. Além disso, o mesmo estudo mostra que alguns ejaculados obtidos na ENR apresentaram baixa concentração espermática ou ainda ejaculados azoospérmicos. Em relação ao ciclo estral da fêmea, sabe-se que a espécie é monoéstrica estacional ${ }^{\mathrm{a}}$. O ciclo estral é de forma geral dividido em proestro, estro, diestro e anestro. O proestro é caracterizado pelo crescimento folicular, estimulado pelos hormônios folículo estimulante (FSH) e luteinizante (LH), liberados pela hipófise. O estro é a fase de receptividade sexual, onde ocorre a ovulação, com diminuição das concentrações de estrógenos e aumento de progestágenos, produzidos pelo folículo em maturação. Já o diestro é a fase de luteinização do folículo, sendo marcado por um aumento gradativo de progesterona, produzida agora pelo corpo lúteo. O anestro é considerado a fase de quiescência, onde o útero involui após uma gestação ou pseudogestação ${ }^{\text {b }}$. Todas essas fases são controladas pelo eixo hipotálamo-hipófise-gonadas (HHG) e qualquer alteração nesse eixo, como por exemplo em casos de hiperatividade do eixo hipotálamo-hipófise-adrenal (HHA) podem interferir diretamente na eficiência reprodutiva. A hiperatividade do eixo HHA é o que caracteriza endocrinologicamente o fenômeno de estresse crônico. Nele, o hipotálamo através da corticotrofina $(\mathrm{CRH})$ induz a liberação do hormônio adrenocorticotrópico (ACTH) que estimula o córtex da glândula adrenal a liberar glicocorticoides. A hiperestimulação do eixo HHA pode inibir o eixo $\mathrm{HHG}$, o CRH pode inibir a liberação das gonadotrofinas (FSH E LH) ocasionando 
assim infertilidade temporária pela não ovulação. Além disso, a exposição prolongada à glicocorticóides pode diminuir a ação do estradiol nos seus tecidos alvo, pela diminuição de seus receptores $^{c}$. Estudos indicam que lobos-guarás de cativeiro apresentam valores basais de metabólitos de corticoesteróides fecais significativamente maiores que os de vida livre, indicando um aumento de atividade adrenocortical e um possível estresse crônico de cativeiro ${ }^{\mathrm{d}}$.

Palavras chave: concentração espermática, estação reprodutiva, estresse crônico, hipotálamohipófise-gonadal.

\section{*REFERÊNCIAS}

${ }^{a}$ DIETZ, J. M. Ecology and social organization of maned wolves, Chrysocyonbrachyurus. Washington DC: Smithsonian Institution press; 1984.

${ }^{\mathrm{b}}$ FEDLMAN, E. C.; NELSON, R. W. Canine and feline endocrinology and reproduction, 3 ed., California, Saunders, 2004. 1099p.

${ }^{c}$ RABIN, D. S.; JOHNSON, E. O.; BRANDON, D. D.; LIAPI, C.; CHROUSOS, G. P. Glucocorticoids inhibit estradiol-mediated uterine growth: possible role of the uterine estradiol receptor. Biology of Reproduction, v.42, p.74-80, 1990.

${ }^{\mathrm{d}}$ SPERCOSKI, K. M., Monitoramento a longo prazo da excreção de corticóides fecais em lobos-guarás (chrysocyon brachyurus, illiger 1811) de cativeiro e vida livre: uma contribuição para o manejo e a conservação da espécie. 2007. 68 f. Dissertação (Mestrado em Biologia Celular e Molecular) - Universidade Federal do Paraná, Curitiba, 2007. 